
A presente publicação resultou das comunicações e debates suscitados pelo I Seminário Luso-brasileiro: Pedagogia, aprendizagem online e tecnologias digitais no ensino superior, dinamizado pelo Grupo de políticas educativas e dinâmicas educacionais (GRUPOEDE) do Centro de Estudos Interdisciplinares do Século XX (CEIS20), pela Unidade Móvel de Investigação em Estudos do Local (ELO) da Universidade Aberta e pela Delegação do Porto da mesma Universidade, que se realizou, em Coimbra, em maio de 2017.

Este primeiro encontro procurou estruturar-se como um espaço de troca de experiências e de reflexão em łorno das questões dos ambientes emergentes de aprendizagem, alicerçados nas tecnologias digitais no contexto do ensino superior. Partindo de experiências de ensino presencial ou à distância, os diversos capítulos debatem o impacto do digital na construção das aprendizagens e na estrułuração dos processos de ensino, na construção de uma didática diferenciada, na emergência de novos paradigmas educacionais, mas sobretudo, procuram mapear caminhos de inovação que se vão construído e consolidando em Portugal e no Brasil. 


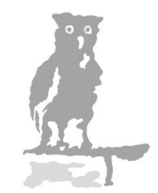

$\begin{array}{lllllllllllll}\text { I } & \mathrm{N} & \mathrm{V} & \mathrm{E} & \mathrm{S} & \mathrm{T} & \mathrm{I} & \mathrm{G} & \mathrm{A} & \mathrm{C} & \tilde{\mathrm{A}} & 0\end{array}$

$\underbrace{}_{\substack{\text { IMPRENSA DA INIERSIDADE DE COIMBRA } \\ \text { COIMBRA LNIVERSITY PRESS }}}$

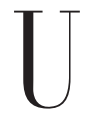




\title{
EDIÇÃo
}

Imprensa da Universidade de Coimbra

Email: imprensauc@ci.uc.pt

URL: http//www.uc.pt/imprensa_uc

Vendas online: http://livrariadaimprensa.uc.pt

COORDENAÇÃO EDITORIAL

Imprensa da Universidade de Coimbra

CONCEÇÃo GRÁFICA

Imprensa da Universidade de Coimbra

\author{
INFOGRAFIA DA CAPA \\ Mickael Silva \\ PRÉ-IMPRESSÃo \\ Jorge Neves \\ PRINT BY \\ KDP
}

ISBN IMPRESSO

978-989-26-1715-2

ISBN DIGITAL

978-989-26-1716-9

DOI

https://doi.org/10.14195/978-989-26-1716-9

(C) SETEMBRO 2019, IMPRENSA DA UNIVERSIDADE DE COIMBRA

SEMINÁRIO LUSO-BRASILEIRO, 1, Coimbra, 2017

Pedagogia e didática com as tecnologias digitais no ensino superior / org. Ana Isabel Ribeiro, Daniela Melaré Vieira Barros. - (Conferências e debates interdisciplinares)

ISBN 978-989-26-1715-2 (ed. impressa)

ISBN 978-989-26-1716-9 (ed. eletrónica)

I - RIBEIRO, Ana Isabel

II - BARROS, Daniela Melaré Vieira, 1950-

CDU 37.01 


\section{PEDAGOGIA E \\ DIDÁTICA COM \\ AS TECNOLOGIAS \\ DIGITAIS NO \\ ENSINO SUPERIOR}

\section{ANA ISABEL RIBEIRO \\ DANIELA MELARÉ VIEIRA BARROS (ORGS.)}


(Página deixada propositadamente em branco) 


\section{Í N D I C E}

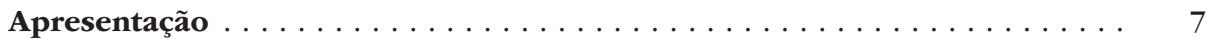

ANA ISABEL RIBEIRO, DANIELA MELARÉ VIEIRA BARROS

Retratos do docente no ensino superior online - pedagogias e tecnologias . .

SUSANA HENRIQUES, J. ANTÓNIO MOREIRA, MARIA DE FÁTIMA GOULÃO

Formação de professores em ambiente virtual: interação e mediação

com tecnologias digitais. . . . . . . . . . . . . . . . .

DAÍSA TEIXEIRA

Aprender a ensinar em ambientes digitais: desafios para a docência

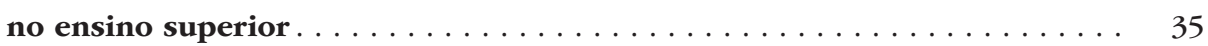

SARA DIAS TRINDADE

Educação online: reflexões e aproximações em busca de fundamentos

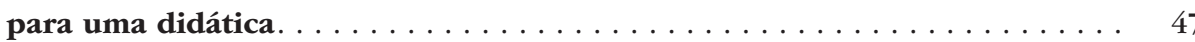

DIENE EIRE DE MELLO

Reflexões sobre educação a distância a partir de Marx: considerações sobre tecnologias e trabalho docente . . . . . . . . . . . . . . . . . 59 ANDRÉ GARCIA CORREAA, LUCIANE PENTEADO CHAQUIME, DANIEL MILL

Letramentos digitais, linguagens, comunicação online e implicações em processos de formação na universidade.

Terezinha Fernandes

As narrativas digitais na formação docente:

entre o proposto e o realizado . 
O hipervídeo na educação online: pensando a autoria de vídeos interativos

VIVIAN MARTINS, EDMÉA SANTOS

A educação cíbrida e as possibilidades para as docências

no ensino Superior: o POMAR em questão

ADRIANA ROCHA BRUNO, ANA CAROLINA GUEDES MATTOS

Formação continuada de professores no Programa Agrinho:

uma experiência formativa em rede.

PATRICIA LUPION TORRES

Elementos da convergência na educação: perspectivas

para o ensino superior. .

FERNANDA ARAUJO COUTINHO CAMPOS, FERNANDO SELMAR ROCHA FIDALGO 
SARA DIAS-TRINDADE

Faculdade de Letras - Depart. de História, Estudos Europeus, Arqueologia e Artes Centro de Estudos Interdisciplinares do Século XX

Universidade de Coimbra

sara.trindade@uc.pt

\section{APRENDER A ENSINAR EM AMBIENTES DIGITAIS: DESAFIOS PARA A DOCENCIA NO ENSINO SUPERIOR}

\section{Introdução}

Uma vez que a tecnologia é hoje uma realidade presente em quase todo o lado, é fundamental que, quer no ensino em geral, quer na formação de professores em particular, se reconheça que

a capacidade que os alunos têm de aceder à informação com a rapidez de um clique ou do deslizar de um dedo, torna o uso de tecnologias [...] na educação cada vez mais uma realidade. Os estudantes do novo milénio estão de tal forma habituados a esta corrente constante de informação que estão "formatados" para pensar, também na escola, de uma forma diferente da de gerações anteriores (Trindade, 2015, p. 207).

De facto, estamos perante uma nova realidade, a de uma geração para quem "sharing is power" (Prensky, 2010, p. 280), para quem o mundo conectado permite o alcance de muito mais informação do que aquela que, há bem poucos anos atrás, seria possível aceder.

Porém, é importante não esquecer que, se para estas novas gerações a utilização da tecnologia é um ato natural e uma constante no seu quotidiano, a maior parte do corpo docente universitário carece ainda de alguma atualização no que diz respeito a práticas que envolvam o uso dessa mesma tecnologia.

Para além disso, é também necessária ao corpo docente uma reflexão sobre as novas necessidades dos seus estudantes, sendo uma mais valia, também, a 
sua articulação com novos ambientes digitais e com todas as vantagens a ele associadas.

Partindo desta perspetiva, e de algumas perceções, em grande parte fruto das reflexões tidas com os nossos próprios estudantes, partimos do pressuposto de que seria importante fazer um estudo empírico a partir de bibliografia recente, nacional e internacional, para perceber de que forma vem sendo encarada a formação de docentes do ensino superior e, sobretudo, qual o papel das tecnologias educativas na atividade docente no ensino superior.

De facto, a nossa perceção inicial acompanha as ideias de Flávia Vieira, que, fruto também da análise de trabalhos de diferentes autores, refere que "embora os docentes e os gestores institucionais valorizem o ensino e a investigação como atividades estruturantes da universidade, a relação entre elas tende a ser conflitual e sobrevaloriza-se a investigação em detrimento do ensino" (2014, p. 24).

Assim, tomámos como ponto de partida Zabalza (2004; 2012), que reflete, precisamente, sobre a necessidade de dedicar atenção à formação dos docentes do Ensino Superior e, também, sobre a importância de que se reveste a difusão de boas práticas, como forma de dotar este corpo docente de sólidos conhecimentos na área da didática e da pedagogia.

E que lugar pode ter a tecnologia nessa mesma formação docente? Esta questão levou-nos através de alguns documentos de renomadas instituições internacionais, como UNESCO, União Europeia e World Economic Forum, para depois confrontar aquelas que são as suas recomendações com o que diferentes autores vêm também defendendo.

\section{Formação de professores do Ensino Superior e Ambientes Digitais}

Em Portugal, tem-se apostado bastante na introdução de ambientes digitais nas escolas do ensino não superior, mas tem sido um pouco mais lenta a sua introdução em ambiente universitário. De facto, apesar de ao longo dos últimos anos ter havido uma aposta crescente por parte das instituições governativas em fornecer formação contínua para que os professores do ensino não superior se atualizassem e conseguissem dominar estratégias assentes em 
diferentes tecnologias digitais, o mesmo não tem acontecido para os docentes do Ensino Superior.

$\mathrm{Na}$ verdade, não tem havido uma grande preocupação com uma formação pedagógica geral de docentes do Ensino Superior, simplesmente por se considerar que a docência é uma atividade eminentemente prática para a qual não serão necessários conhecimentos muito específicos (Zabalza, 2004; Pretto; Riccio, 2010).

De facto, tal como refere Vieira,

as práticas reprodutoras e monológicas de uma universidade que durante séculos constituiu um espaço elitista e homogéneo não respondem às exigências atuais de uma universidade de massas inscrita numa "era de supercomplexidade" que requer uma "epistemologia para a incerteza" (2014, p. 24).

Por esse motivo, surgem hoje algumas preocupações com a formação pedagógica destes docentes, sobretudo decorrentes não só de uma certa massificação e heterogeneidade da população estudantil, mas também dos novos desafios colocados pelo Processo de Bolonha (Marques; Pinto, 2012; Leite; Ramos, 2014).

Estes novos desafios têm vindo a colocar em perspetiva a forma como se ensina nas universidades, que cada vez mais precisam rever as suas pedagogias e a sua didática, proporcionando novas formas de acesso ao conhecimento e à formação por parte dos seus estudantes. De facto, "a intuição e experiência profissional já não são suficientes para gerar recursos para superar os conflitos que este "novo" papel de professor do Ensino Superior cria" (Gaeta; Prata-Linhares, 2013, p. 345). Quer isto dizer que, depois de Bolonha, a componente científica se vê agora a par com a capacidade de dotar os estudantes de competências que vão além da reprodução dos conhecimentos adquiridos e para as quais o recurso a ambientes digitais pode ser uma mais valia.

Aliando as possibilidades didáticas das Tecnologias Digitais ao desenvolvimento de estratégias mais ativas, os docentes podem colocar os seus estudantes frente a novos desafios e ao desenvolvimento de competências chave de ordem superior (como pensamento crítico ou criatividade) e de qualidades de caráter (como iniciativa, adaptabilidade ou persistência) (WEF, 2015). 
É nesse sentido que reporta a UNESCO, ainda no final dos anos 90 do século passado, quando indica que

a educação superior está sendo desafiada por oportunidades novas relacionadas a tecnologias que têm melhorado os modos através dos quais o conhecimento pode ser produzido, administrado, difundido, acessado e controlado. $\mathrm{O}$ acesso eqüitativo a essas tecnologias deve ser garantido em todos os níveis dos sistemas de educação (1998: online).

Perante novas necessidades, em particular devido às competências que cada vez mais são esperadas dos jovens estudantes do século XXI, novas metodologias de ensino têm de ser colocadas em prática pelas instituições de Ensino Superior. Porém, "incorporar experiências e modalidades diversas de trabalho [...] não é, naturalmente, um trabalho fácil; ao contrário disso, exige uma reconstrução do perfil habitual dos professores universitários" (Zabalza, 2004, p. 31).

E, por isso, é neste contexto que a incorporação de estratégias que passam pelas tecnologias educativas ganha maior fôlego, não descurando, obviamente, a necessidade de manutenção de elevados níveis de qualidade das práticas (UNESCO, 1998).

Pensando no facto de que é nas mãos dos docentes universitários que se encontra a formação dos profissionais do futuro (Almeida; Pirasol; Silva; Fernandes, 2015), assume primordial importância o desenvolvimento de metodologias e práticas de ensino que fomentem a criatividade, o espírito crítico e a capacidade de trabalho efetivo por parte dos estudantes que frequentam o ensino superior.

Neste ponto, a componente das tecnologias pode contribuir para a formação do estudante enquanto cidadão completo pois

torna-se evidente nos tempos atuais a existência de uma tendência, não somente do professor, mas da sociedade, em se integrar de forma consciente, compulsória e coercitiva a esse mundo dinâmico das inovações tecnológicas, seja em razão da mídia, de estímulos diversos, da busca de prazer ou da necessidade para a sobrevivência (Lima; Loureiro, 2016, p. 5). 
É por isso necessário enfrentar esta falta de formação docente na área das tecnologias educativas, e dotar estes profissionais de competências para a integração de recursos digitais, de qualidade, nas suas práticas letivas, adequando-as, como é natural, aos objetivos que se pretendem atingir (Lima; Loureiro, 2015).

Não raras vezes, quando se encontram exemplos de utilização de recursos ou práticas que envolvem ambientes digitais, estes apresentam-se reduzidos a novas maneiras de fazer as mesmas coisas, ou seja, sem uma verdadeira consciência de que para uma efetiva integração das TIC nas aulas é necessária uma mudança efetiva das práticas, sobretudo como forma de estabelecer maior proximidade com o estudante, numa lógica de operar uma verdadeira integração entre os seus saberes e os desses mesmos estudantes (Lima; Loureiro, 2016; Trindade; Ribeiro, 2016).

Consciente da relutância encontrada, sobretudo, junto da classe docente com mais anos de serviço, o Livro Branco da Comissão Europeia, publicado em 1995, referia-se já à necessidade de dar a hipótese aos professores de se adaptarem às novas tecnologias, numa era em que os próprios materiais multimédia ainda não eram considerados de grande qualidade para além de que as infraestruturas escolares ainda não estavam preparadas para o uso desse mesmo material (1995). Já mais recentemente, a Comissão Europeia (2013) retoma a questão das tecnologias no ensino, invocando que a sua utilização deve ter um efeito transformativo na forma de encarar o ensino e a aprendizagem.

Neste contexto é necessário que os docentes aceitem a partilha do conhecimento com os seus alunos, configurando-se como "mediadores" do processo de aprendizagem, num contexto em que

não se trata de desarticular os saberes consolidados pela ciência, mas de buscar uma forma de comunicação, interação, colaboração e produção destes conhecimentos por meio do uso de artefactos tecnológicos contemporâneos, permitindo releituras e novas construções a partir destes saberes constituídos (Lima; Loureiro, 2015, p. 5).

De facto, cabe apenas aos docentes perceber que a utilização de tecnologias digitais no ensino se coaduna com os seus próprios objetivos: elas 
podem ser utilizadas na apresentação da informação, se o docente optar por uma estratégia mais "clássica", ou podem estar associadas a estratégias onde o estudante tem um papel mais ativo, através da exploração de conteúdos ou de recurso a metodologias de questionamento (Coll, 2009).

De facto, essas estratégias ditas "clássicas" ainda são as mais procuradas. Chamlian (2003) aborda a questão do confronto entre aquilo que é pensado pela maioria dos académicos como a sua primordial função (a de pesquisa) e o que pretendem os seus estudantes (beneficiar dos resultados gerados a partir dessa mesma pesquisa). E é por isso que se torna cada vez mais premente conseguir que o público docente receba, efetivamente, algum tipo de formação que lhe permita ultrapassar esse "confronto" e, potenciado até pela utilização de recursos digitais, desenvolver práticas "com o objetivo de estabelecer redes comunicacionais de formação e aprendizagem que possibilitem uma aprendizagem dialógica e crítica" (Pretto; Riccio, 2010, p. 162). Neste plano, quanto mais ativo for o papel do estudante, mais centrado estará em si o processo de aprendizagem. Quanto mais o docente encorajar estratégias que coloquem no estudante a necessidade de resolver problemas, experimentar ou tomar decisões, mais necessário se torna o reconhecimento de que se, por um lado, está a fomentar o aumento da autonomia dos seus estudantes, por outro irá ser necessário estar preparado para guiar esses mesmos estudantes em ambientes académicos um pouco mais flexíveis (Casanova; Costa; Moreira, 2012).

Para que isso aconteça, repetimos, torna-se fundamental a formação docente. Há que aceitar que a evolução da tecnologia é uma constante e que, sem qualquer apoio, os docentes ficam reféns de um "fast evolving and chaotic Wild West of digital apps" (Guernsey; Levine; Chiong; Severns, 2012, p. 15).

Koehler e Mishra (2009) referem sobre esta questão, indicando a este propósito que as tecnologias digitais - como computadores, dispositivos móveis e software - são versáteis, instáveis e opacos. Outro problema referido pelos autores, e que complica a relação entre o ensino e a tecnologia é o facto de que as tecnologias não são nem neutrais nem isentas. Mas, por outro lado, têm também os seus potenciais, as suas propensões e as suas restrições que as tornam mais propensas para umas coisas do que outras. $O$ docente passa a ter de saber "desenhar", ou "arquitetar" (Vieira, 2013), ambientes educativos 
onde a tecnologia atue como potenciador da qualidade do processo de ensino e de aprendizagem, sobretudo procurando não utilizar as tecnologias digitais como uma forma diferente de fazer as mesmas coisas.

A esse propósito, refere Fidelix que

um dos aspectos na formação do pedagogo contemporâneo está diretamente relacionado à abertura para acolher as TIC, para que seja possível desenvolver uma prática investigativa articulando os componentes curriculares relacionando as tecnologias ao currículo" (2016, p. 160).

\section{O exemplo da FLUC}

No âmbito do Ensino Superior todas estas questões têm vindo a ser abordadas e novas práticas têm vindo a ser desenvolvidas na Universidade de Coimbra, de forma a desenvolver ambientes mais apelativos e interativos, em linha com as novas necessidades daqueles que estão em processo de se tornarem os profissionais do futuro.

No caso desta Universidade, já há vários anos que se tem procurado adaptar as práticas ao desenvolvimento de ambientes digitais emergentes. Um desses exemplos passa pela integração de conteúdos na plataforma iTunes $U$. Foi mesmo a primeira universidade portuguesa a aderir a esta plataforma de partilha de conteúdos educativos, algo que faz já desde 13 de janeiro de 2011.

Esta plataforma tem sido amplamente utilizada, sobretudo nos EUA, como uma forma de proporcionar a qualquer estudante uma verdadeira aprendizagem "em qualquer lugar". Conteúdos, aulas, mais informações, propostas de trabalhos, ficam disponíveis sob a forma de conteúdos abertos. A estas propostas a Universidade de Coimbra não ficou alheia, integrando os mais variados conteúdos na sua página integrada nesta plataforma.

A Faculdade de Letras tem também vindo a apostar nesta área, havendo vários docentes plenamente virados para uma formação integral e que usufrua das potencialidades das tecnologias.

Exemplo disso pode ser encontrado nos mestrados em Ensino, onde vários docentes têm vindo a trabalhar na área das tecnologias educativas, fazendo 
também investigação variada nesta área e procurando, por um lado, colocar em prática as ideias que têm resultado dessas investigações e, por outro, disseminar esses mesmos resultados como forma de ampliar a sua utilização entre os seus pares. Seguimos, neste propósito, as ideias de Vieira (2014), relativas à "indagação da pedagogia", procurando ser "professores-investigadores que exploram, interpretam, avaliam e disseminam as suas práticas" (Vieira, 2014, p. 26), procurando criar comunidades de prática orientadas para processos de mudança.

Estas práticas têm passado pela utilização de recursos que permitam o trabalho colaborativo entre os alunos, fora da sala de aula, por exemplo criando documentos de trabalho partilhados onde produzem conteúdos relacionados com as aulas. Outro exemplo de trabalho que desenvolvemos na Faculdade de Letras segue a linha da disponibilização da informação em formato digital, acessível em qualquer lugar, nomeadamente tratando-se dos portfólios dos nossos estudantes de Segundo Ciclo dos Mestrados em Ensino. Habitualmente, estes estudantes tinham de ter um dossiê físico onde guardassem todas as informações relativas ao seu trabalho em estágio. Esse dossiê acabava por estar fechado e sem grande acesso pela nossa parte. Assim, começámos a trabalhar com os nossos estudantes na criação de portfólios digitais, aos quais nós enquanto docentes temos acesso e que podemos assim verificar o trabalho que vão desenvolvendo e mesmo comentá-lo, colaborando com os nossos estudantes até mesmo na melhoria da qualidade da sua atividade profissional durante a realização dos seus estágios pedagógicos.

Para além disso, e dado que cada vez mais se vem apostando em estratégias cada vez mais "fora-da-caixa", a Faculdade tem apetrechado salas de aula com equipamentos variados, como o Laboratório de Línguas, ou a sala HTML (História, Tecnologias e Mobile Learning), na qual pretendemos desenvolver trabalhos de projeto com os nossos alunos, utilizando equipamentos agora muito associados às chamadas "salas do futuro". Estas salas estão vocacionadas, essencialmente, para o ensino não superior mas o nosso objetivo é colocar os nossos estudantes a preparar conteúdos que permitam, a posteriori a sua fruição nesses ambientes educativos. Ou seja, pretendemos colocar os nossos alunos a "pensar" como fazer chegar a informação e o conhecimento a outros. 
A ideia é, de facto, colocar em prática o trabalho colaborativo e utilizar os mecanismos tecnológicos que temos ao nosso dispor para aceder à informação e agrupá-la, exercendo, para o efeito, trabalho de pesquisa, seleção da informação e análise, ou seja, trabalho colaborativo e também crítico. Isto porque nos parece que esta será a melhor forma de construírem os seus próprios conhecimentos: tendo de os tornar claros e acessíveis para outros.

Diferentes docentes receberam também formação para trabalhar com este tipo de equipamentos e estratégias, sempre numa lógica de disseminar e melhorarmos quer as práticas docentes quer os resultados alcançados.

\section{Reflexões Finais}

Zabalza referia que "la praxis tiene por objetivo transformar la realidad y mejorarla" (2012, p. 23). É, de facto, um desafio procurar compreender onde e como podemos atuar de forma a contribuir para a melhoria das práticas pedagógicas no Ensino Superior.

Constatada a inevitabilidade de adaptar e atualizar a pedagogia neste nível de ensino, fruto não só da necessidade de adequação a novos mercados e a um público muito mais heterogéneo, o professor universitário deve ser um "arquiteto da pedagogia" (Vieira, 2013), alguém capaz de "desenvolver movimentos contra-hegemónicos de participação proativa dos docentes na reconfiguração da sua profissionalidade e do estatuto da pedagogia" (Vieira, 2013, p. 141).

Se, como lembra António Nóvoa (2013), a Educação é sempre colocada (a nível de instituições como a União Europeia) como o centro de todas as soluções, a Educação Superior deve ser encarada como a reta final desse processo educativo, onde os docentes se encontram perante estudantes prestes a entrar no mundo profissional.

Neste contexto, entendemos que as práticas pedagógicas podem ser potenciadas por um uso informado e construtivista da tecnologia, numa colaboração estreita entre a difusão de conhecimento científico e o desenvolvimento de competências-chave e de qualidades de caráter (WEF, 2015), através de práticas que fomentem, nos futuros profissionais, uma cidadania ativa e plena num mundo que também ele é cada vez mais digital. 


\section{Referências bibliográficas}

ALMEIDA, S.; PIRASOL, S.; SILVA, W.; FERNANDES Jr., A. (2015). Mediação pedagógica e o uso de tecnologias no ensino superior. In XII Congresso Nacional De Educação (EDUCERE), III Seminário Internacional De Representações Sociais, Subjetividade E Educação (SIRSSE), Formação de professores, complexidade e trabalho docente. (pp. 21954-21968). Curitiba: Champagnat. Disponível em: http://educere.bruc.com. br/arquivo/pdf2015/19537_9035.pdf (Acedido em 27/04/2017)

CASANOVA, D.; Costa, N. \& MOREIRA, A. (2012). Aprendizagem potenciada pela tecnologia no ensino superior: uma metodologia para o desenvolvimento de critérios de qualidade. In C. Leite \& M. Zabalza (coord.). Ensino Superior: inovação e qualidade na docência (pp. 4219-4234). Porto: CIIE.

CHAMLIAN, H. C. (2003). Docência na Universidade: professores inovadores na USP. Cadernos de Pesquisa, 118, 41-64.

COLL, C. (2009). Aprender y enseñar con las TIC: expectativas, realidad y potencialidades. In R. Carneiro, J. C. Toscano, T. Díaz (coord.). Los desafios de las TIC para el cambio educativo (pp. 113-126). Madrid: Fundación Santillana.

COMISSÃO EUROPEIA (1995). Livro branco sobre educação e formação: ensinar $e$ aprender: rumo à sociedade cognitiva [COM(95) 590 final]. Bruxelas: Serviço de Publicações da Comissão Europeia. Disponível em: https://infoeuropa.eurocid.pt/ registo/000037230/documento/0001/ (Acedido em 27/04/2017)

COMISSÃO EUROPEIA (2013). Abrir a Educação: Ensino e aprendizagem para todos de maneira inovadora graças às novas tecnologias e aos Recursos Educativos Abertos [COM (2013) 654 final]. Bruxelas: Serviço de Publicações da Comissão Europeia. Disponível em: http://www.ipex.eu/IPEXL-WEB/dossier/files/download/082dbcc5 40a5439001416e35239b249b.do (Acedido em 27/04/2017)

FIDELIX, C. (2016). Formação inicial de professores: tecnologias no currículo das instituições de ensino superior do município de SP. In Congresso Regional sobre Tecnologias na Educação, Brasil, 23-25 de maio 2016 (pp. 158-169). Rio Grande do Norte: Universidade Federal do Rio Grande do Norte.

GAETA, M. C. D. \& PRATA-LinHARES, M. M. (2013). Formação de professores do Ensino Superior: experiências curriculares em cursos Lato Sensu. Olhar de Professor, 16(2), 343-355.

Guernsey, L.; LeVIne, M.; ChIONG, C.; SEVERns, M. (2012). Pioneering literacy in the digitak wild west: empowering parents and educators. Washington, DC: Campaign 
for Grade-Level Reading. Disponível em: http://gradelevelreading.net/wp-content/ uploads/2012/12/GLR_TechnologyGuide_final.pdf (Acedido em 27/04/2017)

KOEHLER, M. \& MISHRA, P. (2009). What is technological pedagogical content knowledge (TPACK)? Contemporary Issues in Technology and Teacher Education, 9(1), 60-70.

LEITE, C. \& RAMOS, K. (2014). Políticas do Ensino Superior em Portugal na fase pós-Bolonha: implicações no desenvolvimento do currículo e das exigências ao serviço docente. Revista Lusófona de Educação, 28, 73-89.

LIMA, L. \& LOUREIRO, R. (2015). A utilização das tecnologias digitais da Informação e Comunicação no contexto da docência no Ensino Superior. In Anais Online do IX Colóquio Internacional Educação e Contemporaneidade, 17-19 setembro 2015 (s. p.) Aracaju: Universidade Federal de Sergipe.

LIMA, L. \& LOUREIRO, R. (2016). Formação de professores no ensino superior: integração entre tecnologias digitais e docência. In Atas do III Congresso Nacional de Educação, 5-7 outubro 2016 (s.p.). Campina Grande: Realize Eventos \& Editora Disponível em: http://www.editorarealize.com.br/revistas/conedu/resumo. php?idtrabalho=1546 (Acedido em 27/04/2017)

MARQUES, J. \& PINTO, P. R. (2012). Formação pedagógica de professores do Ensino Superior - a experiência na Universidade Nova de Lisboa. Revista Portuguesa de Pedagogia, 46(2), 129-149.

NóvOA, A. (2013). The blindness of Europe: New fabrications in the European educational space. Sisyphus Journal of Education, 1(1), 104-123.

PRENSKY, M. (2010). Teaching digital natives: partnering for real learning. California: Corwin.

PRETTO, N. \& RICCIO, N. (2010). A formação continuada de professores universitários e as tecnologias digitais. Educar, 37, 153-169.

TRINDADE, S. D. (2015). O passado na ponta dos dedos: o mobile learning no ensino da História no 3. ${ }^{\circ} \mathrm{CEB}$ e no Ensino Secundário (Dissertação de Doutoramento não publicada). Faculdade de Letras da Universidade de Coimbra, Coimbra.

TRINDADE, S. D. \& RIBEIRO, A. I. (2016). Universidade de Coimbra digital: visitas de estudo guiadas por tablets. In N. Pedro et al (orgs.), Digital Technologies E Future School (pp. 179-188). Lisboa: Instituto de Educação da Universidade de Lisboa.

UNESCO (1998). Declaração Mundial sobre Educação Superior no Século XXI: Visão e Ação - Conferência Mundial sobre Educação Superior - UNESCO, Paris, 9 de outubro de 1998. Disponível em: http://www.direitoshumanos.usp.br/index.php/ 
Direito-a-Educa\%C3\%A7\%C3\%A30/declaracao-mundial-sobre-educacao-superior-no-seculo-xxi-visao-e-acao.html (Acedido em 27/04/2017)

VIEIRA, F. (2013). O professor como arquiteto da pedagogia na universidade. Revista Teias, 14(33), 138-156.

VIEIRA, F. (2014). Para uma mudança profunda da qualidade da pedagogia na universidade. REDU, Revista de Docência Universitária, 12(2), 23-39.

WEF-World Economic Forum (2015). New Vision for Education: Unlocking the Potential of Technology. Cologny/Geneva: World Economic Forum.

ZABALZA, M. A. (2004). O ensino universitário: seu cenário e protagonistas. São Paulo: Artmed.

ZABALZA, M. A. (2012). El estudio de las "buenas prácticas" docentes en la enseñanza universitaria, REDU, Revista de Docência Universitária, 10(1), 17-42. 